\title{
Managing Knowledge in Shared Spaces
}

\author{
Ganesh D. Bhatt' ${ }^{1}$ Pankaj Pankaj' ${ }^{2}$ James A. Rodger ${ }^{2}$ \\ ${ }^{1}$ Department Information Systems, Morgan State University, Baltimore, MD, USA \\ ${ }^{2}$ Information Systems \& Decision Sciences, Indiana University of Pennsylvania, Indiana, PA, USA \\ Email: ganesh.bhatt@morgan.edu, Pankaj@iup.edu, jrodger@iup.edu
}

Received 23 July 2014; revised 22 August 2014; accepted 10 September 2014

Copyright (C) 2014 by authors and Scientific Research Publishing Inc.

This work is licensed under the Creative Commons Attribution International License (CC BY). http://creativecommons.org/licenses/by/4.0/

(c) (i) Open Access

\begin{abstract}
Information has always been an integral component of business strategy. However, with the rise of information technology (IT) and globalization of businesses, information has taken a far more important role in explaining business performance. IT can be used to enhance research activities of the firm; and its product knowledge can be used to improve business productivity. In fact, scholars and researchers have indicated that knowledge can be a source of sustainable advantages for the firm. However, not much research has been done that explains what kind of knowledge is important for sustainable advantages. In this paper, we present three kinds of knowledge: core, complementary, and peripheral. We also develop an idea of shared space along three dimensions: physically shared space, technically shared space, and cognitively shared space. The main theme of this paper is to show the relevance and importance of these different kinds of knowledge along the shared spaces that create sustainable advantages for the firm.
\end{abstract}

\section{Keywords}

Knowledge Management, Information Technology, Shared Space, Firm Performance

\section{Introduction}

There is a renewed interest in the importance of knowledge management. Information technology (IT) and globalization of businesses have been main contributors of this interest. A great deal of research has been done to show the importance of knowledge in business strategies. The current strand of research suggests that many of the performance differences between firms are influenced by the resources and capabilities in which firms have invested. The understanding of the dependence on past capabilities leads to a view of path-dependence, which means a firm's capabilities involve building on knowledge what it already knows how to do [1]. In addition, a firm can incorporate new knowledge based on its absorptive capacity, which is confined based on its existing knowledge-base [2] [3]. 
Although research has explained several aspects of knowledge, there are still several questions that remain unanswered. We still do not know what kind of knowledge is the most important for sustainable advantages for the firm and how a firm can enhance the effectives of this knowledge for its use. By taking this research, we attempt to fill the gap in the literature by explaining three kinds of knowledge - core, complementary, and peripheral, and three kinds of shared spaces - physically shared space, technically shared space, and cognitively shared space. We argue that even though each kind of knowledge has some contribution to the advantages of the firm, but the contribution of knowledge is enhanced when it is shared along a space that is easy to share and provides impetus to work in collaboration [4].

This article proceeds in the following manner. First, we discuss the three kinds of knowledge: core, complementary, and peripheral. Next, we provide an explanation of shared space along three dimensions: physically shared space, technically shared space, and cognitively shared space. Then we show how different perspectives of spaces become critical in enhancing the effectiveness of knowledge for firm performance. It is true that IT is an important contributor of developing and opening-up of these spaces, but IT alone is not sufficient to increase the effectiveness of knowledge for business advantages. There needs to be a fit between the space and knowledge. Next, we set a number of propositions and in the final section; we discuss the implications of the fit for knowledge management and suggest some ideas for future research.

\section{Literature Review}

Knowledge and information are intertwined, but they are not the same thing. For example, IT may facilitate in exchanging of information that may (or may not) lead to combination of knowledge. To make sense of knowledge, the perspective of space becomes critical, because knowledge does not exist in vacuum [5]. Therefore, to make sense of knowledge, it must exist in a specific space. A space provides the context of shared meanings. In addition, sharing of knowledge requires a common language for its understanding. Therefore, an important aspect of any discussion of knowledge must consider three things: common space, cognitive abilities to understand knowledge, and a shared language. While common space allows the means of sharing knowledge, cognitive abilities determine one's ability to make sense of knowledge; and shared knowledge provides a means of conversation among different aspects of knowledge. All of the above requirements are important in knowledge management. Without a shared space, knowledge becomes inert. Similarly, limitations on cognitive abilities make it difficult to appropriately evaluate useful knowledge [6]. Common Language refers to the sharing of ideas through meaningful codes. When knowledge is shared and transferred in different codes, making sense of knowledge often becomes difficult [7].

\section{Shared Space}

A shared space can be defined as a locus of the relationship between different actors and participants who engage in to achieve a particular goal or desired action. In this sense, a shared space articulates about the viability and interpretability of knowledge, and is open. With the proliferation of IT and globalization of businesses, the importance of the shared space has become a key ingredient for the business advantages. The reason for it is that the shared space is sensitive to external information as well as responsive for dealing with unusual situations. In addition, a shared space offers a venue to combining knowledge from different perspectives and compressing the integrated information to provide a holistic view of knowledge. In a shared space, knowledge is, therefore, becomes a part of the space [8]. Below we define three kinds of shared spaces.

\subsection{Physically Shared Space}

The simple aspect of shared space for knowledge creation and utilization takes place at the physical level. Sharing space at the physical level allows participants a shared schema of norms and rules through which they engage with people inside the physical space and others that they believe are outside of their physical space. The physical space cannot be completely divorced from external information. On the contrary, physically shared space should be structured in such a way as to allow the flow of critical knowledge and information from one place to another. Physically shared places emphasize on the stickiness of the knowledge that often becomes difficult to share through explicit rules and information. In this case, knowledge is shared through apprenticeship [9]. A physically shared space provides a sense of belonging that is quite different from belonging to technically 
shared space as well as cognitively shared space. Even in a public transport or an airline, when a traveler is assigned a seat, he/she usually feels free to read a magazine, play with a computer, and do small official chores from the seat.

\subsection{Cognitively Shared Space}

A shared space may also be conceptualized as either static or dynamic. A static view of the shared space often makes it difficult for two actors to switch the places. These spaces could be inherited either by birth or through dense family ties. For example, in a cast system as used in India, the actors can't move across their cast systems, except through the interracial marriages.

In a dynamic shared space, an actor can move up and down in the hierarchy based on their performance and irrespective of their expertise. For example, an executive may enter an organization on a particular career path but finds that he/she is continually promoted irrespective of his/her primary area of expertise. However, it must be realized that the nature of the space also articulates the cognitive schema of the actors who belong to a space. Cognitive schema also determines one's ability to make sense of what is before us, and how cognitive limitations impact the ability to convert information into knowledge. The sense of a shared cognitive schema may also come through the belonging to a cognitively shared space regardless of its physical proximity. In this respect, a physical space can be an enabler for creating a shared schema among the organizational members.

Cognitively shared spaces are critical for converting tacit knowledge into explicit knowledge. Since tacit knowledge is difficult to articulate, it becomes critical that participants share common background and understanding of the problem. Cognitively shared spaces represent the ability to communicate, understand, and interpret knowledge. It also provides opportunities for joint creation of meaning and value. Sense making paradigms lead us to think that organizations are not passive actors in knowledge creation activity, rather they actively participate in knowledge creation activity by enacting a shared meaning through participation [10].

\subsection{Technically Shared Space}

Technically shared space is transparent for allowing its participants to reflect and interact with the technology. The software simulations and other technological tutorials provide a means of interacting technologically and in turn learn new knowledge. In addition, technology has also provided means to share information among individuals. Chat rooms, simple messaging, bulletin boards, and many private and public forums have become to exchange information and learn and understand each other's perspectives for creating new knowledge.

A technically shared space refers to simulated or virtual space, which allows participants to interact together and understand the meaning of information [11]-[13]. Technically shared space is based on the availability of artificial communication tools. It requires technical infrastructures that are often configured distinctively by each organization to facilitate efficient knowledge sharing. However, over time, these infrastructures become common and can be viewed as commodities that depreciate in value and become more cost-effective and ubiquitous. Technically shared space allows knowledge to be more easily codified because protocols become standardized.

Technically shared space is usually created through information systems. With rapid development in the communication and computing media, participants around the world can carve their own virtual shared space that allows them to interact with subjects of interest. Chat rooms, multimedia, videoconferencing, and discussion forums are some tools that provide this kind of virtual space

A technically shared space can reduce the cost of processing, distributing, and sharing information. This reduces the cost of coordination, increases information availability and processing capacity, and facilitates monitoring and controlling the performance of other participants in the relationship. Technically shared spaces help to capture informal communications, personal-experiences, and personal interpretations. It facilitates communications and discussions, leading to collective learning between different organizational members [14].

\section{Knowledge}

Scholars working in strategic planning and organization theory areas have defined knowledge as justified belief that enhances one's capacity for effective action [15]. A careful examination of this definition helps in clarifying the following finer points. First, knowledge is essential for the effective action; second, beliefs are perceived through the mind or memory of the knower; third, knowledge is gained through the experience since experience 
is the precursor of the effective action. Some scholars, however, go beyond the current state of the effective action. They view knowledge as a capability of influencing the future action by being able to manipulate information, interpret processed information, and use the interpreted information for effective action [16]. In this paper, we prefer a capability perspective of knowledge, because we focus on the process of new knowledge creation and we believe that each organization is endowed with differential capabilities in manipulating, interpreting, and using the information. Putting in other words, we believe that even if organizations attend same events or stimuli, they would still create different levels of knowledge. This perspective brings forth the following suggestions in the design of an IS for knowledge creation.

\section{Organizational Knowledge}

When individual knowledge is shared, and amplified from a group setting to the organization setting, it becomes organizational knowledge. Though a part of organizational knowledge is created through individual knowledge, organizational knowledge is not a simple sum of individuals' knowledge. Organizational knowledge involves as continual interplay between explicit knowledge and tacit knowledge that is amplified as knowledge moves through individual, and group to organizational levels. Knowledge development in organizations takes place through four modes of knowledge conversion [17]. The conversion can be from explicit to explicit, explicit to tacit, tacit to explicit, and tacit to tacit. In the first mode of conversion, from explicit to explicit, information can be used to transfer and convert explicit knowledge into easier formats. For example, in routine and programmed activities, organizations can make use of standard templates to process explicit knowledge effectively [18]. Different kinds of communication media such as face to face meetings, communication networks, electronic document transferring, and telephone conversations can be used to transfer explicit knowledge into different combinations.

In the second mode of conversion, explicit to tacit, information sharing provides the ground for internalizing explicit knowledge into tacit actions. However, before everyone in the organization can make use of such knowledge, individuals at all levels are required to be socialized for providing a shared-mental schema of the task. Information sharing makes the process of socialization easier and allows members to internalize the experiences through learning by doing [19].

In the third mode of conversion, tacit to explicit, information is mostly used to compose different analogies and metaphors for the creation of new knowledge. Even though tacit knowledge possessed by individuals in organization cannot be codified easily and imitated by competitors [20] [21], the mobility and idiosyncrasies of experts can be too demanding to assimilate into organizational culture effectively. Therefore, organizations strive to create an environment that would make it simpler to convert tacit rules and knowledge into explicit knowledge. This can be done by making organizational routines simpler to work with. For example, highly specific main-frame commands, which were under the purview of some experts in the organization, are replaced by powerful window PCs.

In the last mode of knowledge conversion, from tacit to tacit, information is used for brainstorming, debating, and socialization purposes. Because tacit knowledge is mostly associated with personal expertise or experience, it becomes critical that this kind of knowledge is used throughout the organization. By using different dialectical means of information processing such as critiques, challenges, and debates, tacit knowledge can be reconfigured so that it can be used throughout the organization. This is usually common for those companies that continually generate and process information about their products, services, customers, and work-procedures to create new knowledge.

\section{Types of Knowledge}

We categorize knowledge as core, complementary, and peripheral. The core knowledge explains the beliefs and goals of the organization that are generally agreed upon, and helps employees to understand strategies, purpose and mission. Core knowledge is the foundational thoughts and ideas that create the commonality of interest and shared purpose, and is embedded into an organization's employees, products, processes, and technologies. It contains knowledge about the most basic of the organization's purposes and goals, and is critical to organizational success [22] [23]. Core knowledge is important for competitive advantages, because it is based on unique history of the firm, causal ambiguity and social complexity [24].

Complementary knowledge is a part of knowledge that remains inert until it is assimilated with other half of 
the knowledge, which often remains outside of organizational boundary. Complementary knowledge can be purchased from the market, since complementary knowledge obtains its meaning only when it is linked with the existing complementary part of knowledge in the organization. Organizations often benchmark against each other and select superior organizations' rules and standard procedures. In this sense, an organization can acquire some of the knowledge from outside and tries to combine it with its existing complimentary knowledge [25]. The part of complementary knowledge once acquired and assimilated with existing complementary knowledge, it enables an organization to earn superior revenue stream. In this sense, combining complementary knowledge provides a holistic view of the environment and of the situations.

Peripheral knowledge does not directly add value to the firm, but its importance is still considered as a key since it motivates a firm to acquire complementary knowledge. More often, peripheral knowledge can still guide a firm toward the improvement on core knowledge. The reason is that many of the signals and responses elicited from peripheral knowledge directly impact core knowledge as well as complementary knowledge [25] [26].

\section{Analytical Framework}

Within a physically shared space, when people share the same space in an organization, they are more likely to share core knowledge [27]. Although personnel also possess complementary and peripheral knowledge individually, but at the organizational level, they are more likely communicate core knowledge [28].

Because core knowledge is essential for the advantage of the firm, it must be easily shared within the organization. On the other hand, it must not easily be accessible across competitive organizations. Physical space becomes a necessity to create such a paradoxical demand. Therefore, we hypothesize:

Hypothesis 1: Given the space in which core knowledge exists, core knowledge should be shared within a physical space.

Complementary knowledge in itself is inert. However, it becomes valuable when it is coupled with another piece of the complementary knowledge, so that a firm can gain a holistic picture of the reality [29].

Complementary knowledge can also be examined from the perspective of relatedness. Relatedness is the degree of similarity between what is already known, what is being learned, and its application. The organization accumulates knowledge over time that includes experiences about specific events. As this knowledge is employed over time, it becomes more refined and tailored to the organization's unique needs. Refining of complementary knowledge allows for the core knowledge to be better applied at some later stage and for similar problems to be avoided.

Often it becomes important that an organization make use of complementary knowledge from external sources. This can be done through collaborative efforts and cooperation among different organizations. Technical space can be an important facilitator to add the value to cooperative ventures. By sharing the work through distributed team across different organizations, a better solution of the important problems can be found, which in turn, likely to add value for each of the firm involved in the collaboration [30].

Given the importance of complementary knowledge for finding a holistic picture of the reality, it is important that IT infrastructure across the sharing firms be flexible. Sharing of critical information across cooperative firms is important for combining complementary knowledge across different organizations. Therefore, we hypothesize:

Hypothesis 2: Given the space in which complementary knowledge exists, complementary knowledge should be shared within a technical space.

The concept of a complementary is used to extend the scope of core and complementary knowledge. Although peripheral knowledge in itself does not directly contribute to organizational advantages, it is not considered inert. The reason being that peripheral knowledge is an impetus to continuously improve core knowledgebase as well as complementary sets of knowledge bases that exist across different organizations.

The use of a cognitive space is essential for increasing the effectiveness of peripheral knowledge. Cognitive space is essential because it highlights the different levels of mental thinking among the organizational members. Cognitive space enables a basis for understanding different point of view. Often organizational leaders try to subdue or reduce this kind of different thinking among organizational members. However, to enhance the effectives of core knowledge and complementary knowledge, peripheral knowledge is important [31]. Accordingly, we develop the following hypothesis:

Hypothesis 3: Given the space in which peripheral knowledge exists, peripheral knowledge should be shared 
within a cognitive space.

\section{Discussion and Future Research Directions}

We argue that three kinds of knowledge: core, complementary, and peripheral knowledge are intertwined. However, each of these knowledge requires different kinds of arenas for expression so that a firm can maximize their effective use. When core knowledge is linked with complementary knowledge, these linkages become source of the competitive advantages to the firm, but it does not mean that peripheral knowledge is unimportant. In fact, many cases, peripheral knowledge sensitizes the organization for making sense of the core and complementary knowledge. If peripheral knowledge is removed, the firm often becomes slow in learning new knowledge that could be important for its advantages. In fact, in many cases, knowledge combination takes place only in light of the peripheral knowledge. Similarly, the importance of three kinds of space is important for having a context of knowledge that can be interpreted and shared among the organizational members.

While physical space provides the adequacy of secrecy of core knowledge, technical knowledge facilitates the distribution of complementary knowledge, and cognitive space provides a common avenue for sharing, interpreting, and believing the importance of peripheral knowledge, these spaces do not remain rigid nor do they are completely isolated from each other. These spaces, in fact, are intertwined and often making clean separation among them is difficult. However, for a theoretical purpose, it is still important to understand these spaces as separate region.

Future research can look at the boundaries among these spaces and make a finer categorization of various kinds of spaces. Future research can also look into how different kinds of knowledge moves across these spaces. How these spaces leads to the risk of hoarding knowledge among organizational members, leaking private knowledge to outside competitors, and creating confusion of information loads become an important area of inquiry for future research. And also, what kind of knowledge fits to what kind of space is another important area that needs to be researched in the future.

\section{Conclusions}

In this paper, we have argued that knowledge is a shared concept. It can exist only within a shared space which provides a context to interact with. Shared spaces can be of three kinds: physically shared space, technically shared space, and cognitively shared space. These shared spaces are not exclusive, but for theoretical purposes, they have been defined separately. We have also provided an understanding of different kinds of knowledge: core knowledge, complementary knowledge, and peripheral knowledge.

The main argument of our paper is that a shared space is essential for knowledge creation and enhancing the effectiveness of knowledge combination for business advantages. Physically shared space represents close proximity and allows sharing of emotions and sentiments. Cognitively shared space does not necessarily require close proximity, except sharing a broad premise. Those who are part of cognitively shared space must think along the shared premise and be able to share some common language. The commonality of language eases problems of translation and communication while contributing to the development of cognitively-based communities of practice. Technically shared space is more tuned toward sharing of explicit knowledge to a community of practitioners. Although sharing knowledge technically can provide the advantages of efficiency, it can create the problems in making the sense of knowledge. Therefore, where knowledge is impersonal and can be represented in blue-prints, technical means can be quite useful in capturing and transferring such kind of knowledge. On the other hand, where knowledge is sticky and deals with personal values and directly relates to human, technical means, in addition, require the use of physical means and cognitive means for sharing knowledge [32].

In general, core knowledge is mostly interactive, shared within a physical arena; complementary knowledge is mostly shared through technically shared space; and peripheral knowledge requires an understanding of cognitive space [33] [34]. Certainly, we cannot clearly categorize knowledge along these spaces, as the relevance of knowledge changes with context and the environment. Still it makes sense to understand that not all kinds of knowledge should be shared and interacted same way. Critical knowledge should be shared within a physical space to the employees because in an open space this kind of knowledge can be used by the competitors. On the other hand, complementary knowledge in itself is not that relevant until it is used in combination with the other part of knowledge. In this aspect, technical space can provide better avenues for sharing complementary piece of 
knowledge. Cognitive space has an important role in supporting the use of peripheral knowledge. Since often a firm does not adequately support peripheral knowledge, the importance of peripheral knowledge cannot be unnoticed. In several cases, peripheral knowledge enables a firm to acquire, interpret, and use core knowledge [35]. Therefore, a firm is required to take adequate step in supporting those people in the organization that may have different ideas and notions and may be referred as the "outliers".

\section{References}

[1] Dosi, G., Nelson, R.R. and Winter, S.G. (2000) The Nature and Dynamics of Organizational Capabilities. Oxford University Press, Oxford.

[2] Barney, J. (1991) Firm Resources and Sustained Competitive Advantage. Journal of Management, 17, 99-120. http://dx.doi.org/10.1177/014920639101700108

[3] Bhatt, G.D. (2000) A Resource-Based Perspective of Developing Organizational Capabilities for Business Transformation. Knowledge and Process Management, 7, 119-129. http://dx.doi.org/10.1002/1099-1441(200004/06)7:2<119::AID-KPM87>3.0.CO;2-Z

[4] Nonaka, I. (1994) A Dynamic Theory of Organizational Knowledge Creation. Organization Science, 5, 14-37. http://dx.doi.org/10.1287/orsc.5.1.14

[5] Nelson, R.R. and Winter, S.G. (2002) Evolutionary Theorizing in Economics. Journal of Economic Perspectives, 16, 23-46. http://dx.doi.org/10.1257/0895330027247

[6] Weick, K.E. (1979) The Social Psychology of Organizing (Topics in Social Psychology Series). McGraw-Hill, Inc., New York.

[7] Weick, K.E. and Roberts, K.H. (1993) Collective Mind in Organizations: Heedful Interrelating on Flight Decks. Administrative Science Quarterly, 38, 357-381. http://dx.doi.org/10.2307/2393372

[8] Foss, N.J. (1996) Knowledge-Based Approaches to the Theory of the Firm: Some Critical Comments. Organization Science, 7, 470-476. http://dx.doi.org/10.1287/orsc.7.5.470

[9] Porter, M.E. (2000) Location, Competition, and Economic Development: Local Clusters in a Global Economy. Economic Development Quarterly, 14, 15-34. http://dx.doi.org/10.1177/089124240001400105

[10] Schlesinger, I.M. (2006) Cognitive Space and Linguistic Case: Semantic and Syntactic Categories in English. Cambridge University Press, Cambridge.

[11] Swan, J., Newell, S., Scarbrough, H. and Hislop, D. (1999) Knowledge Management and Innovation: Networks and Networking. Journal of Knowledge Management, 3, 262-275. http://dx.doi.org/10.1108/13673279910304014

[12] Rosenberg, M.J. (2001) E-Learning: Strategies for Delivering Knowledge in the Digital Age. Vol. 9, McGraw-Hill, New York.

[13] Sang, G., Valcke, M., van Braak, J. and Tondeur, J. (2010) Student Teachers' Thinking Processes and ICT Integration: Predictors of Prospective Teaching Behaviors with Educational Technology. Computers \& Education, 54, $103-112$. http://dx.doi.org/10.1016/j.compedu.2009.07.010

[14] Zettsu, K., Nakanishi, T., Iwazume, M., Kidawara, Y. and Kiyoki, Y. (2008) Knowledge Cluster Systems for Knowledge Sharing, Analysis and Delivery among Remote Sites. Frontiers in Artificial Intelligence and Applications, 166, 282-289.

[15] Nonaka, I. and Toyama, R. (2003) The Knowledge-Creating Theory Revisited: Knowledge Creation as a Synthesizing Process. Knowledge Management Research \& Practice, 1, 2-10. http://dx.doi.org/10.1057/palgrave.kmrp.8500001

[16] Barney, J.B. (2001) Resource-Based Theories of Competitive Advantage: A Ten-Year Retrospective on the ResourceBased View. Journal of Management, 27, 643-650. http://dx.doi.org/10.1177/014920630102700602

[17] Nonaka, I. and Takeuchi, H. (1995) The Knowledge-Creating Company: How Japanese Companies Create the Dynamics of Innovation. Oxford University Press, Oxford.

[18] Nelson, R.R. and Winter, S.G. (2009) An Evolutionary Theory of Economic Change. Harvard University Press, Cambridge.

[19] Powell, W.W. and Snellman, K. (2004) The Knowledge Economy. Annual Review of Sociology, 30, 199-220. http://dx.doi.org/10.1146/annurev.soc.29.010202.100037

[20] Teece, D.J. (1998) Capturing Value from Knowledge Assets. California Management Review, 40, 55-79. http://dx.doi.org/10.2307/41165943

[21] Teece, D.J., Pisano, G. and Shuen, A. (1997) Dynamic Capabilities and Strategic Management. Strategic Management Journal, 18, 509-533.

[22] Grant, R.M. (1996) Prospering in Dynamically-Competitive Environments: Organizational Capability as Knowledge 
Integration. Organization Science, 7, 375-387. http://dx.doi.org/10.1287/orsc.7.4.375

[23] Bolzani, D., Fini, R., Grimaldi, R., Santoni, S. and Sobrero, M. (2014) Fifteen Years of Academic Entrepreneurship in Italy: Evidence from the Taste Project.

[24] Tallman, S., Jenkins, M., Henry, N. and Pinch, S. (2004) Knowledge, Clusters, and Competitive Advantage. Academy of Management Review, 29, 258-271.

[25] Breschi, S. and Malerba, F. (2006) Clusters, Networks, and Innovation. Oxford University Press, Oxford.

[26] Hedlund, G. (2007) A Model of Knowledge Management and the N-Form Corporation. Strategic Management Journal, 15, 73-90. http://dx.doi.org/10.1002/smj.4250151006

[27] Cooke, P. (2001) Clusters as Key Determinants of Economic Growth. In: Mariussen, Å., Ed., Cluster Policies-Cluster Development? Nordregio Report, Stockholm, 23-38.

[28] Conner, K.R. and Prahalad, C.K. (1996) A Resource-Based Theory of the Firm: Knowledge versus Opportunism. Organization Science, 7, 477-501. http://dx.doi.org/10.1287/orsc.7.5.477

[29] Coriat, B. and Weinstein, O. (2002) Organizations, Firms and Institutions in the Generation of Innovation. Research Policy, 31, 273-290. http://dx.doi.org/10.1016/S0048-7333(01)00141-X

[30] Gil, A.J. and Carrillo, F.J. (2014) Knowledge Transfer and the Learning Process in Spanish Wineries. Knowledge Management Research \& Practice, Published Online. http://dx.doi.org/10.1057/kmrp.2014.12

[31] Terziovski, M. (2010) Innovation Practice and Its Performance Implications in Small and Medium Enterprises (SMEs) in the Manufacturing Sector: A Resource-Based View. Strategic Management Journal, 31, 892-902.

[32] Prahalad, C.K. and Hamel, G. (1990) The Core Competence of the Corporation. Harvard Business Review, 68, 79-91.

[33] Pemsel, S. and Müller, R. (2012) The Governance of Knowledge in Project-Based Organizations. International Journal of Project Management, 30, 865-876. http://dx.doi.org/10.1016/j.ijproman.2012.02.002

[34] Garrido-Moreno, A. and Padilla-Meléndez, A. (2011) Analyzing the Impact of Knowledge Management on CRM Success: The Mediating Effects of Organizational Factors. International Journal of Information Management, 31, 437444. http://dx.doi.org/10.1016/j.ijinfomgt.2011.01.002

[35] Weiss, J. and Brown, R.S. (2013) The Challenge of Changing Curriculum Stories over Time, in Telling Tales over Time. Springer, Berlin, 169-182. 
Scientific Research Publishing (SCIRP) is one of the largest Open Access journal publishers. It is currently publishing more than 200 open access, online, peer-reviewed journals covering a wide range of academic disciplines. SCIRP serves the worldwide academic communities and contributes to the progress and application of science with its publication.

Other selected journals from SCIRP are listed as below. Submit your manuscript to us via either submit@scirp.org or Online Submission Portal.
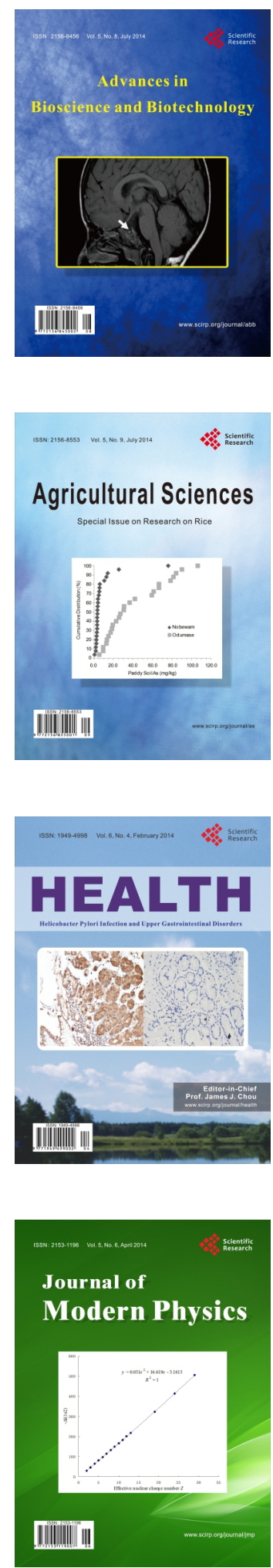
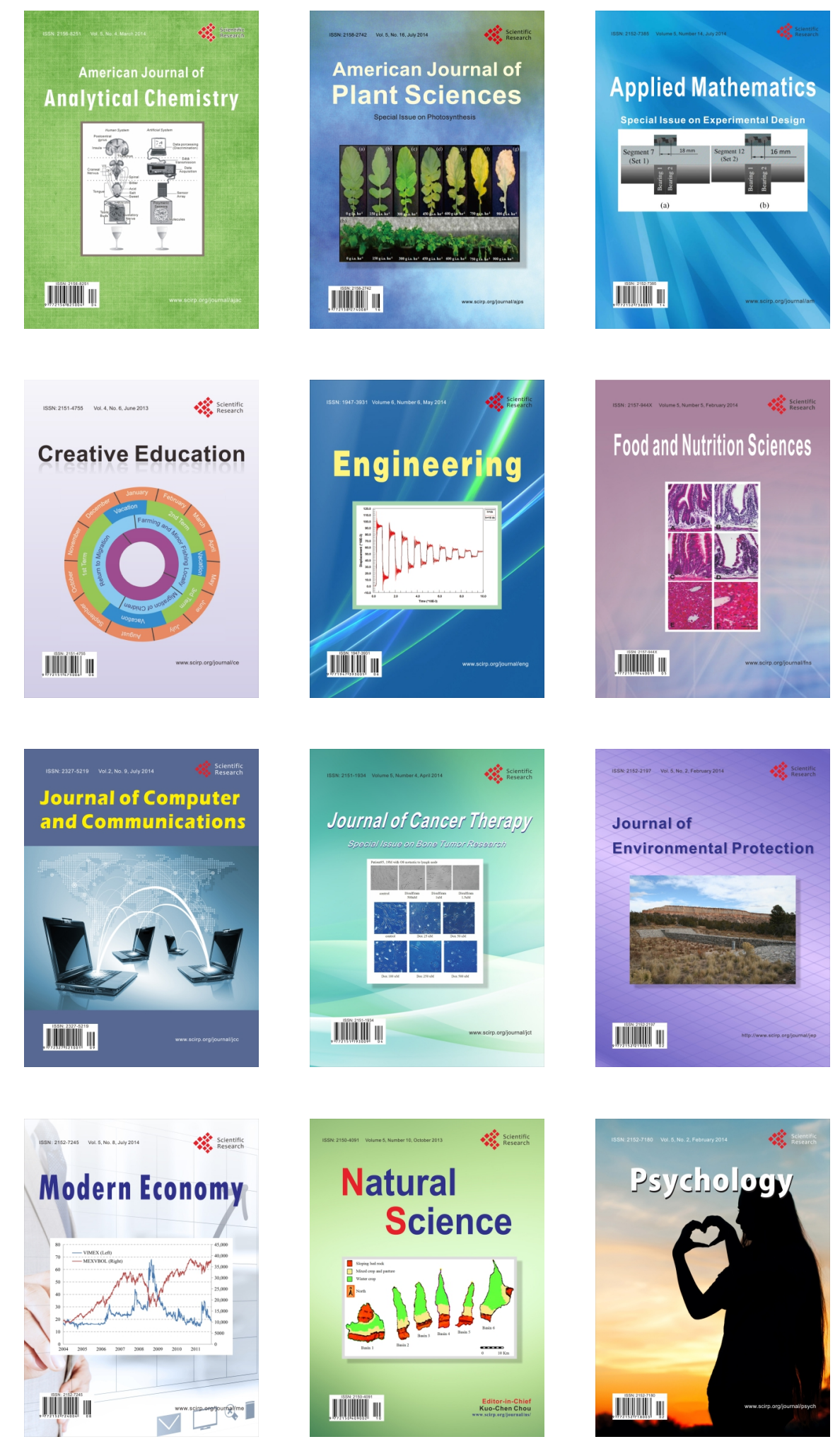